\title{
PGE Prospecting Features by Results of SP and Geoelectrochemistry Methods
}

\author{
Natalia Senchina
}

\begin{abstract}
Platinum-group elements (PGE) prospecting can be carried out with use of geochemical or geophysical methods. Geochemical methods can study objects located at the surface only, and geophysical methods are not always effective because of too low concentrations of PGE in the host rocks do not change the ores physical properties. Geoelectrochemical methods are suitable for deep-lying ores prospecting. Problem of movable forms creation of passive PGE can be fixed takin into account natural electrical processes. It is shown by laboratory experiment and tested during field works. Laboratory data confirmed the influence of electric current on the transition of PGE dozens presents in the dissolved form. The complex geophysical and geoelectrochemical surveys was carried out on the territory of Aganozerskiy (South Karelia), Svetloborskiy and Kachkanar (Middle Urals) massifs containing PGE mineralization. Preconditions for the creation of self-potential (SP) anomalies of redox nature are allocated within these massifs and characteristics of self-potential anomalies are investigated. SP sources are prerequisite for the mobile PGE forms halos creation if they are close to platinum mineralization zones. Moving up in the jet halos by natural ionic flotation mechanism and capillary rise in a circle of meteoric water evaporation and seepage can form zones of elevated concentrations of PGE secondary fixed forms near the surface, which can be detected by different geoelectrochemical methods. It can be concluded that geoelectrochemical methods are not always effective, but in the presence of sources of SP in a geological environment. The interpretation of the geoelectrochemistry anomaly for noble metals should take into account the effect of activators of the mobile forms formation.
\end{abstract}

Keywords: Geoelectrochemistry, self-potential method (SP), platinum group elements (PGE), intrusions with platinum mineralization.

\section{INTRODUCTION}

The objective of this work is to propose an effective substantiated methodology for searching for overlapped or deep-lying platinum-mineralized areas located within platinum-bearing intrusions. The presence of platinum-bearing massifs buried under a layer of glacier rock or other sediments is typical, for example, in the North-West of Russia, Finland and neighboring territories.

The prospecting of overlapping platinum-bearing zones within the intrusion is a rather difficult task due to the fact that geochemical methods make it possible to study objects located at the surface within a few meters in depth, while no

Revised Manuscript Received on May 15, 2020.

* Correspondence Author

Dr. Natalia Senchina*, Department of geophysical and geochemical methods of prospecting and exploration of mineral deposits, St. Petersburg Mining University, Russia. Email: senchina_np@pers.spmi.ru

(C) The Authors. Published by Blue Eyes Intelligence Engineering and Sciences Publication (BEIESP). This is an open access article under the CC BY-NC-ND license (http://creativecommons.org/licenses/by-nc-nd/4.0/) information is available about deep-lying ores. At the same time, geophysical methods of prospecting and exploration are not always effective in the prospecting of platinum-group elements (PGE) deposits because of low concentrations of PGE in the host rocks do not change the physical properties of PGE ores so much that this is reflected in physical fields observed on the surface. An exception is some ore-formation groups (sulfide, titanomagnetite, chromite, etc.), which are characterized by a close spatial relationship between the distribution of PGE and minerals, which give contrast anomalies according to the results of electrical, magnetic, and gravity exploration. However, in this case as well, the direct dependence of the PGE concentrations by the presence and characteristics of sulfide, chromite, and titanomagnetite ore bodies is not always acceptable, as a result - prospective areas of the PGE can be omitted.

\section{GEOELECTROCHEMICAL METHODS}

Geoelectrochemical methods combine the advantages of geophysical and geochemical methods for studying the geological environment. Methods that allow studying mobile and secondary-fixed forms of elements [1]. It is called «geoelectrochemical methods» in Russia; abroad, the methods of mobile forms studying are not separated from wide group of different geochemical methods. Autor, according to the Russian literature, highlights «geoelectrochemical methods with material registration» (another is electrical registration), which include: the CHIM (partial metal extraction), MOSF (method of organometallic soil forms), TMGM (thermomagnetic geochemical method) and others [4]. Methods studies movable form of metals, transporting by jet halo (sectional shape is shown at Fig.1) [2].
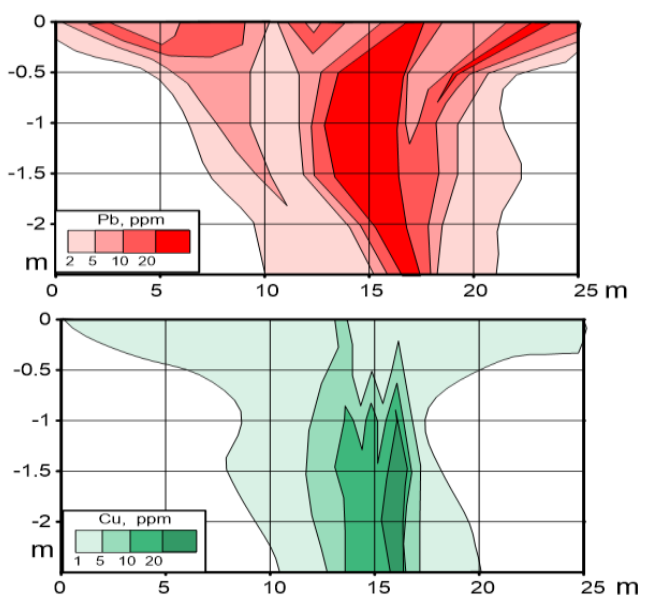

Fig.1. Sectional shape of a jet halo near the ground surface [2]

Published By:

Blue Eyes Intelligence Engineering

\& Sciences Publication

DOI: 10.35940/ijmh.I0868.054920

Journal Website: $\underline{\text { www.ijmh.org }}$ 


\section{PGE Prospecting Features by Results of SP and Geoelectrochemistry Methods} rationale for the application of geoelectrochemical methods is not obviously justified. This is due to the fact that the elements of the platinum group weakly interact with other substances and a very small fraction of PGE passes into the dissolved mobile form, therefore, a halo of scattering of mobile forms of PGE does not form under ordinary conditions. A passivating effect is exerted by films formed on the surface - oxygen, hydroxide, organic and inorganic nature, adsorbed individual chemicals. However, the occurrence of an electrochemical reaction with the formation of the possibility of active transfer of PGE into the dissolved form is possible - it is necessary to remove the film mechanically, chemically or electrochemically [5].

Thus, the phenomenon of distant migration in the jet halos (Fig. 1) or by other mechanisms (diffusion, convection) cannot be substantiated without the involvement of additional mechanisms responsible for the transformation of platinum group metals from solid minerals fixed in the movable. There are a number of conditions under which sharply increases the share of platinum group metals is converted in a dissolved form. So, the process is highly affected by dispersibility of the particles. For example, dust particles produce mobile forms much more intensely than larger grains. Also affect the physico-chemical properties (acidity, redox potential), which is substantially volatile in the near-surface conditions (in connection with the oxidation of organic substances) and even greater on sites of modern ore formation (under the influence of hot fluids during hydrothermal ore genesis). At depths, location in Mature sought platinum-bearing intrusions of the areas that potentially can be discovered and developed; the transition from the PGE to mobile form can affect the self-potential (SP) anomalies, in particular, the redox origin.

The presence of important SP anomalies at Kachkanar, Aganozerskiy, Svetloborskiy platinum-bearing massifs are shown the data of field observations. The study of SP anomalies (and, in part, a comparison with the data of magnetic survey) has allowed to establish that the formation of their associated with zones of the section, enriched (>20\%) magnetite and titanomagnetite. These zones are elongated vertical conductors with a considerable degree of electronic conductivity. While in the ion-conductive environment with variable depth redox properties, which depend on widely observed changes in the concentration of oxygen in the section, these bodies become a «natural galvanic elements». In print, there are links to other mechanisms of formation of high-amplitude SP anomalies, including those associated with the presence of disseminated sulphide mineralization without a continuous electrical connection at depth between the grains, the electronic conductor, or filtration processes.

\section{METHODOLOGIES AND RESULTS}

\section{A. Laboratory data}

Under the influence of electric currents which are produced in the host rocks natural electric fields become intense transition of platinum, palladium set forth in the solid phase of rocks form in a dissolved form. To confirm the relationship conducted a laboratory experiment similar to experiment I. S. Goldberg et al [3], which studied the extraction of some metals (excluding platinum-group metals) of the samples of rocks and ores under the influence of electric current. Experimental conditions differ from natural
When considering prospectinges for PGE deposits, the

conditions using finely crushed ore and a high current density. This is not typical of natural processes, but allows to reduce time of a laboratory experiment to 2 weeks. For the analysis of samples taken at certain intervals of time from the nearest to the electrodes of the cells. The elemental composition of samples was determined in laboratory "Geoekochim" (high-sensitivity ICP analysis, the sensitivity threshold for PGE - 0,001 $\mu \mathrm{g} / \mathrm{l}$ ).

The results of this experiment (Fig. 2) showed that the share of platinum group metals that go into a dissolved form of solid rock sample, is quite high - up to first tens of percent. Obviously, this value is variable depending on the physico chemical properties of solutions, duration of exposure and the strength of an electric current. Revealed that platinum was transferred into the solution predominantly composed of positively charged ions, whereas for palladium dominates the shift in the composition of negatively charged ions. Depending on time, concentration of platinum, palladium and other elements in solution does not change linearly, and speed - probably, in connection with the transition in a solution of particles of minerals with different degrees of fixation elements. Thus, confirmed the influence of electric current on the transition of the PGE in the dissolved form. The complexity of the theoretical justification of the transition from the PGE to mobile form in solution associated with the usual for PGE occurrence of complex formation, especially in bright conditions close to real (not the interaction of the pure substances, as in General chemistry, and the interactions in complex multicomponent geochemical environment).

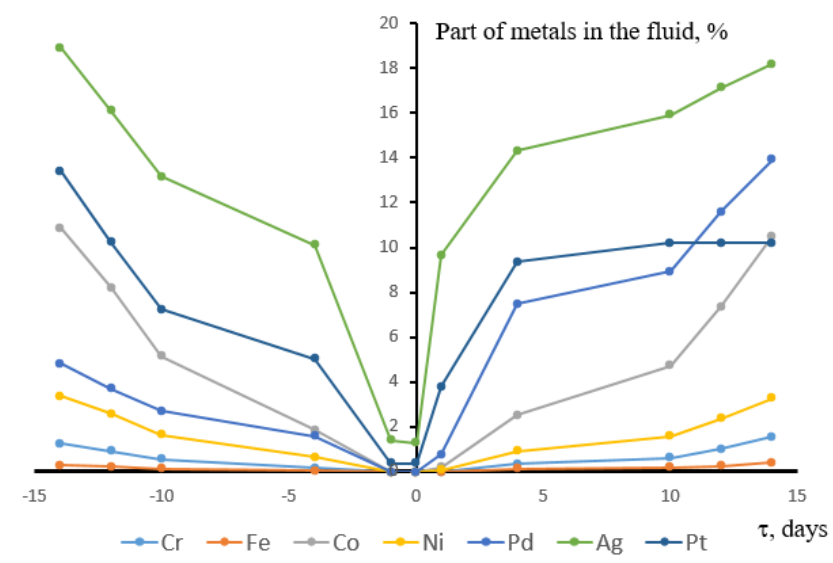

Fig.2. General (integral) transition of some elements from a sample of solid crushed rock into a solution under the influence of electric current (as a percentage of the initial mass in the rock). The half-axis of "negative values" of time means taking samples of catholyte, "positive" - anolyte

The presence of platinum in the adjacent part of the section of the pore solution, high concentrations of mobile forms of platinum group metals is contributing to their dissemination under the action of diffusion, convection, biologic forces (plant roots), in the composition of jet halos.

Last important from the point of view of prospectinging deep platinum-bearing zones occurring on the surface of the anomalies, elevated concentrations of secondary fixed forms of PGE.

Published By:

Blue Eyes Intelligence Engineering

\& Sciences Publication

DOI: 10.35940/ijmh.I0868.054920

Journal Website: www.ijmh.org

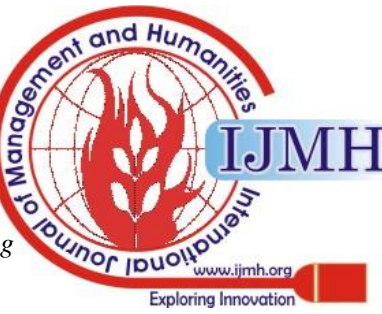


The study of the processes of formation of halos of elevated concentrations of mobile forms of various elements independently carried out by Russian and foreign specialists $[4,6,7,8,9]$. In the end, it was developed several related hypotheses, covering gas bubble convection, the movement of "fast ions", migration under the action of electric current, seismic "injection", the capillary rise in a series of "evaporation-percolation of meteoric waters". The author is inclined to the theory of the formation of these halos by a vertical jet of halos, formed by the mechanism of ion flotation of mobile forms of elements at the microscopic bubbles of undissolved gas rising from the depths to the surface under the Archimedes force [4]. Since the density of gas bubbles less than the density of groundwater, the bubbles rise upward in the section, and the microscopic size of the bubbles allows to penetrate even through the thick conning bed. The electric double layer at the contact surface of the vial containing bubble solution leaves simple and complex ions and a bottle of "pulling" them up. Details of theoretical and experimental substantiation of the theory can be gleaned from the works of O. F. Putikov. The detailed description of the main features identified geoelectrochemical the methods of the study of superimposed haloes, in relation to the standard lithochemical surveying, based on the study of the total contents of chemical elements. The main conclusions of the work can be summarized as follows $[1,4,6]$.

1. Jet scattering halos spread over considerable distances in the subvertical direction, which allows for a greater depth of prospecting.

2. Abnormally elevated concentrations of metals in superimposed halos, as a rule, are confined to the projection of the end parts of ore bodies on the day surface. The shape of superimposed halos can change under the influence of tectonic disturbances of a hard nature.

3. The elemental composition of the superimposed halos corresponds to the material composition of the ores.

4. Anomalies of geoelectrochemical methods distinguish not only the ore objects themselves, but also the structural and tectonic elements of the earth's crust associated with them, in particular, faults (Fe, Mn).

Effect of electric field on the ion motion substantially only in a local region near a powerful source of SP, as the speed of movement of the ion in the composition of the bubble in the rest of the incision is much larger than the speed of movement under the influence of an electric field. As a result, ions do not have time to move to a sufficient distance under the influence SP, and are fixed on the surface of the bubble and entrained in the upward movement. Only in the immediate vicinity of the source of the SP (the size of this area depends on the magnitude of the electromotive force of the source, the electrical resistivity of rocks) dominated by the movement of ions under the influence of current and possible accumulation of chemical elements in some areas near the source. The approximate size of the specified region can be evaluated as the first meters, since the field strength SP decreases with increasing distance from the source fast enough (for a point charge is inversely proportional to the square of the distance).

Thus, it is established that the formation of a deep jet haloes of platinum group metals associated with the natural phenomenon of ion flotation, which is a seizure of chemical elements in mobile forms of presence pop-up gas bubbles and the ion transfer at the interface of liquid and gaseous phases of the bubble. The speed of the front of the jet halo scattering is estimated as $3 \mathrm{~km} / \mathrm{million}$ years. The theory requires in close proximity to ore bodies of the respective elements in ionic form, in the case of PGE is true in a narrow physical and chemical conditions, because these metals are experiencing a very weak interaction with the environment and under normal conditions in the dissolved form are formed in only very small concentrations. This problem is eliminated when you consider the impact of the EF on the extraction of PGE from the fixed form in thin.

\section{B. Field work}

In the framework of testing the hypothesis of the participation of electrochemical processes in epigenetic displacement of the platinum group metals was performed a complex of geophysical works in the territory of Aganozerskiy (South Karelia), Svetloborskiy and Kachkanar (Middle Urals) massifs containing PGE mineralization. Analysis of the geoelectrochemical reprospecting results, magnetic survey data, the self-potential anomalies and methods of investigation of physical and chemical soil properties (Eh, pH, magnetic susceptibility before and after magnetizing roasting) allowed to confirm the justification for the transfer of platinum group elements in mobile form the influence of the self-potential electric fields. For Aganozerskiy, Svetloborskiy and Kachkanar massifs in the result of the relevant works at four plots, the author obtained the anomalies of the mobile forms of PGE, correlated with negative anomalies of the SP or slightly shifted relative to each other.

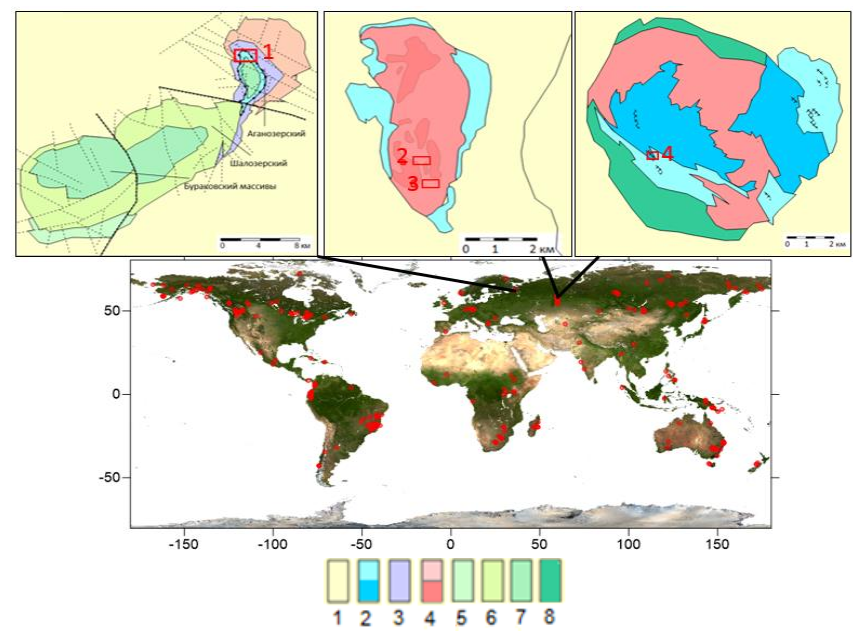

Fig.3. The platinum-bearing massifs of the world position and the schematic geological structure of the massifs (from left to right: Burakovskiy complex (plot 1), Svetloborskiy (plots 2, 3) and Kachkanar massif (plots 4)). Legend (with a generalization): 1 - porphyrites, 2 - ferrogabbronorites, 3 pajonite gabbronorites, 4 - gabbronorites, 5 - dunites, medium and coarse-grained, 6 - peridotites, 7 - pyroxenites and ore (on titanomagnetite) pyroxenites; 8 - enclosing massifs of rocks.

The rocks of the massifs are well differentiated and contain extended along the stratification (zoning) of the region enriched in magnetite (concentration of magnetite (titanomagnetite) - 20-85\% by weight).

DOI: 10.35940/ijmh.I0868.054920

Journal Website: www.ijmh.org
Published By:

Blue Eyes Intelligence Engineering

\& Sciences Publication

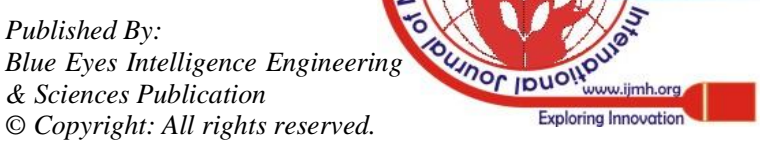


When the content of magnetite more than 5-10\% of enriched magnetite zone can be a digital guide. In addition, the constantly occurring magnetite is an accessory mineral of basic and ultrabasic massifs, composes enriched zones of different geometry - tabular, wedge-shaped deposits, veins, blotches, clusters in the form of veinlets. The most contrasting area of the change of the Eh of interstitial water associated with the transition from the unsaturated zone to the saturated zone pore space groundwater. However, below the section change is observed the redox properties in connection with the penetration by diffusion of the dissolved gaseous oxygen in groundwater.
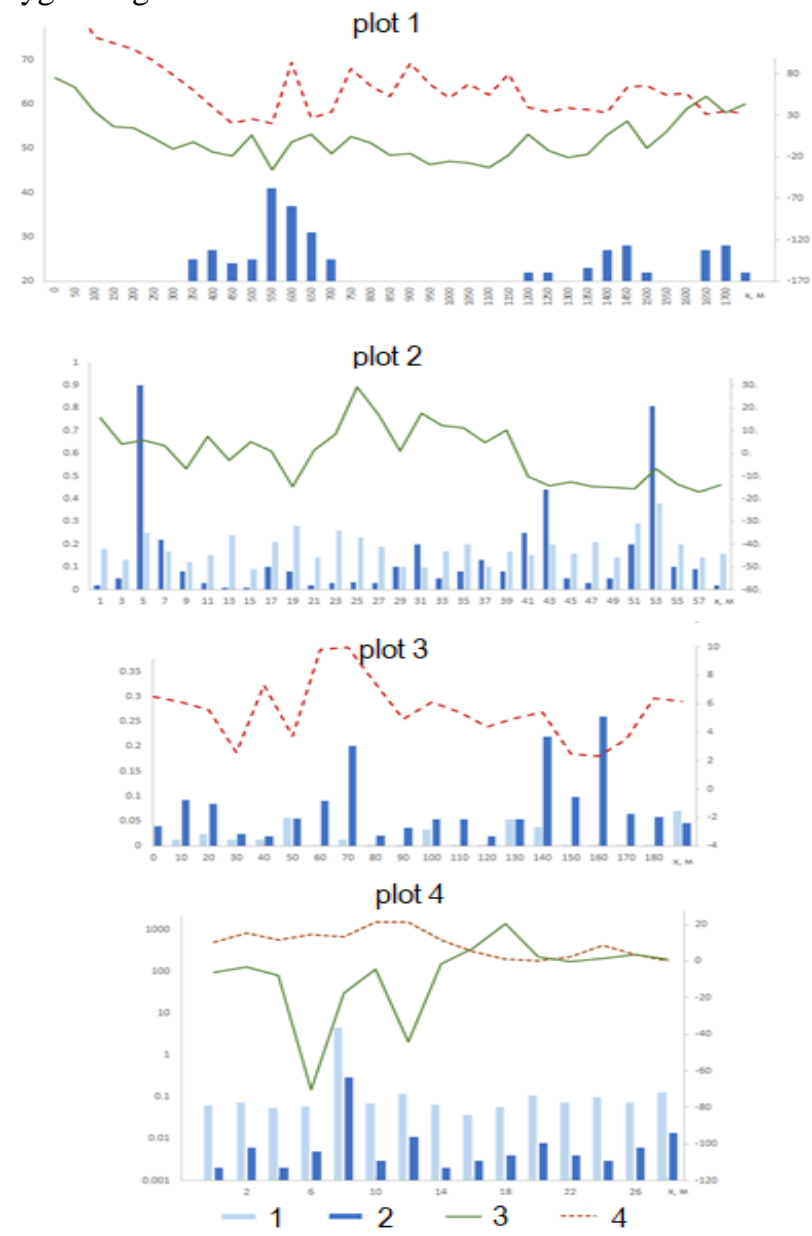

Fig.4. The results of the self-potential anomalies recording (3, $\mathrm{mV}$, right axis), mobile form concentration of platinum (1) and palladium (2) by TMGM (ppb, left axis), the magnetic susceptibility after firing (4, c.u., right axis)

The oxidation of the electron conductor, occurring in the upper part of the body $\left(4 \cdot \mathrm{Fe}_{3} \mathrm{O}_{4}+\mathrm{O}_{2} \rightarrow 6 \cdot \mathrm{Fe}_{2} \mathrm{O}_{3}\right)$, lead to the natural formation of a galvanic element of the electric field source, the magnitude of the electromotive force of which is associated primarily with the value of the differential concentration of oxygen deeper into the cut. In the upper part of the electron conductor is formed an oxidizing atmosphere, and the lower the recovery. The source of self-potential anomalies of redox origin forms around itself an electric field, which can cause a transition platinum group metals in dissolved form as part of the composition ions in a complex case in the region of the field effect fall platiniferous zone. Thus, near the sources of the SP anomalies formed the preconditions for the formation of halos with higher concentrations of mobile and secondary fixed forms of PGE.
These same areas are marked by peculiarities of physical-chemical properties - Eh, pH, magnetic susceptibility before and after firing, - describing the consumption of oxygen for oxidation; but in various degrees complicated by "noise" associated with surface conditions (e.g., waterlogged).

\section{RESULT AND DISCUSSION}

In summary, it is concluded that under the influence of SP to platinum group elements can turn into mobile form, subvertical up and move over long distances and can form zones of high concentrations of secondarily-fixed and poorly fixed forms at the surface. This data can be observed by «geoelectrochemical methods with real registration». The disadvantages of the considered hypothesis from the point of view of prospecting the PGE can be attributed to the local nature of the impact of the SP. In the absence of SP effects, halos of mobile forms of PGE should not be observed, even if the presence of a PGE mineralization at the depth. So, there is evidence of a lack of abnormalities secondary fixed forms of platinum group metals on the platinum-bearing zone, while the observed anomaly of mobile forms of other elements associated copper-nickel mineralization. Refer to the field observations.

\section{CONCLUSION}

Thus, the classical interpretation of geoelectrochemical on the platinum group metals will be mixed due to the influence of anomalies of self-potential anomalies. In the absence of SP anomalies in the vicinity of PGE mineralization zone it can be found very low concentrations of PGE and will not be generated anomalies captured geoelectrochemical methods and requires additional accounting for this factor.

\section{REFERENCES}

1. Alekseev S.G., Veshev S.A., Voroshilov N.A., Putikov O.F., Savitsky A.P., Shtokalenko M.B. The technology of work and interpretation of the data of geoelectrochemical methods at ore objects (methodological recommendations) of the Federal State Institution NPP Geologorazvedka, St. Petersburg, 2005 (in Russian).

2. Dukhanin A.S., Alekseev S.G., Senchina N.P. The structure of jet halo of dispersion of deep-lying deposits of the Ore Altai. Regional geology and metallogeny. 2019.No 80. P. 75-94 (in Russian).

3. Goldberg I.S., Alekseev S.G., Weikher A.A., Gracheva T.R., Electrochemical extraction of elements from rocks, Sat. Methods of exploratory geophysics. Research and application of physico-chemical and geoelectrochemical processes in the search and exploration of minerals. 1982 - p. 62-81 (in Russian)

4. Putikov O. F. Fundamentals of the theory of nonlinear geoelectrochemical methods of prospecting and exploration. St. Petersburg State Mining Institute. SPb., 2009.534 p. (in Russian).

5. Radomsky S.M., Radomskaya V.I. Equilibrium parameters of the process of oxidation of noble metals // Natural and Technical Sciences. 2010. No. 4. P. 166-170 (in Russian).

6. Shtokalenko M.B., Putikov O.F., Alekseev S.G., Veshev S.A., Voroshilov N.A. Evaluation of the parameters of jet migration along the width of the halo of the secondly fixed forms of chemical elements // Geophysics. - No. 4. - 2006- P. 55-60 (in Russian)

7. Cin-Ty A. Lee, Gerald J. Wasserburg and Frank T. Kyte, Platinum-group elements (PGE) and rhenium in marine sediments across the Cretaceous-Tertiary boundary: Constraints on Re-PGE transport in the marine environment, Geochimica et Cosmochimica Acta. - Vol. 67, No. 4, 2003, P. 655-670.

Published By:

Blue Eyes Intelligence Engineering

\& Sciences Publication

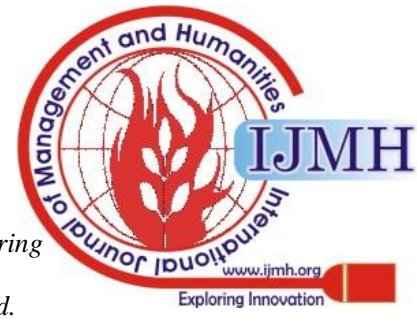


8. Ian R. Pumer H. M. Prichard et al. (eds.). New Mechanisms for the Mobilization of the Platinum Group Elements in the Supergene Zone, Geo-Platinum 87, 1987, P.83-92

9. Kéiko H. Hattori and Eion M Cameron, Using the High Mobility of Palladium in Surface Media in Exploration for Platinum Group Element Deposits: Evidence from the Lac des Iles Region, Northwestern Ontario, Economic Geology Vol. 99, 2004, P. 157-171.

\section{AUTHOR PROFILE}

Natalia Senchina - associate professor at the Department of geophysical and geochemical methods of prospecting and exploration of mineral deposits, St. Petersburg Mining University, Russia. Natalia has graduated the "National mineral resources university (University of mines)" in 2013, specializing in "Technology of geological exploration". She took part in contracts with Kinross gold (Canada), the Chukotka Mining and Geological Company, and PhosAgro, FSUE "Geologorazvedka". Participated in the exhibition PDAC (Prospectors \& Developers Association of Canada, Toronto), passed an internship at the Mining and Metallurgical Academy named by Stanislav Staszic in Krakow, Poland. Natalia has more than 6 years of experience in geophysics and geochemistry and more than 30 publications. Member of EAGS, EAGE, editorial member of two journals.

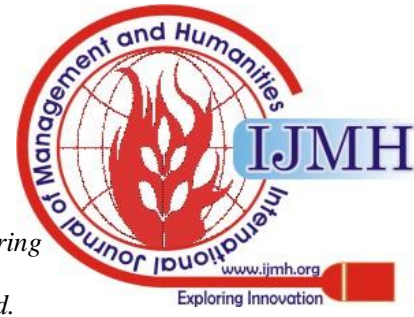

